\author{
Andrew Rhodes \\ Jean-Daniel Chiche \\ Rui Moreno
}

\section{Improving the quality of training programs in intensive care: a view from the ESICM}

Received: 22 November 2010

Accepted: 28 November 2010

Published online: 14 January 2011

(C) Copyright jointly held by Springer and ESICM 2011

A. Rhodes $(\square)$

Department of Intensive Care Medicine,

St George's Healthcare NHS Trust and St Georges

University of London, London SW17 0QT, UK

e-mail: andyr@sgul.ac.uk

Tel.: +44-208-7255699

\section{J.-D. Chiche}

Réanimation Médicale and Dept de Biologie Cellulaire, Hopital COCHIN-APHP and Institut Cochin,

Université Paris Descartes, 27 rue du Faubourg Saint-Jacques,

75679 PARIS Cedex 14, France

e-mail: jean-daniel.chiche@ cch.aphp.fr

Tel.: +33-1-58412739

\section{R. Moreno}

Unidade de Cuidados Intensivos Polivalente,

Hospital de St. António dos Capuchos,

Centro Hospitalar de Lisboa Central, E.P.E,

Lisbon, Portugal

e-mail: r.moreno@mail.telepac.pt

Tel.: +351-3153784 great pressures to increase our capacity to care for critically ill patients, in part because of the changing demographics of the populations and in part due to the altered perceptions of what can be ultimately achieved [3]. The need for our knowledge and skills will therefore be greater than ever before and it is concerning to note that the future demand has been predicted to exceed what we are likely to be able to deliver $[4,5]$. For this reason perhaps more than any other, we need to ensure that we can train the next generation of intensive care doctors to the right standards and in the necessary numbers. This training needs to provide each individual with the required knowledge, skills, attitudes and behaviours to be able to deliver ICM with the quality and safety our patients deserve and that society demands.

The evolution of ICM as a specialty in its own right has occurred at different speeds around the world. In Australia, ICM is now governed by the College of Intensive Care Medicine. This college is responsible for ensuring that the standards of training are at the appropriate level and that accreditation of the training schemes is adequate. The college is also responsible for ensuring that the assessment of an individual's training is complete through an examination. Similar (but not identical) mechanisms for the governance and development of the specialty have occurred in Canada and are beginning to develop in many countries within Europe. This year the UK is developing its own faculty of ICM that will have similar roles and responsibilities to the Australian College. The development and subsequent implementation of homogenous standards for training and accreditation of ICM doctors across Europe, however, have proven to be far more challenging.

Within the European Union (EU), the organisation and delivery of health services and medical care is a fundamental responsibility of each member state (MS), a principle known as subsidiarity. This principle has been enshrined into the developing legislation within the EU 
framework and individual MSs actively work to maintain this constitutional right. Active harmonization of MS public health legislation by the EU, on the whole, remains prohibited. This complicates the development of health policy at the European-wide level and makes reforms that aim to improve education, training and standards of care across Europe more difficult. Through directives that target other areas of interest, European legislation may, however, have a profound impact on healthcare delivery at the MS level. The European Working Time Directive (2003/88) and the Directive describing the recognition of professional qualifications (2005/36), both Directives that were not originally designed to change health delivery, have had a major influence on the design and running of training programs for ICM throughout Europe. Because of all of the factors described above, there is still a great deal of heterogeneity in the standards of education and in the assessment modalities of the training schemes for ICM at the European level. Besides obvious consequences in terms of quality of care provided and patient safety, this also impacts the ability for professionals to freely move and practice their profession within the EU free market area.

As an international scientific organization, the European Society of Intensive Care Medicine (ESICM) is not empowered to directly enforce changes in training schemes in any country, whatever their underlying quality. However, the ESICM can develop standards and provide innovative educational and assessment tools to stimulate improvement of locally run training schemes. Owing to its central trans-national position, the ESICM can also lobby and influence policy change at the EU level to try and ensure that similar levels of training scheme quality can be achieved from whatever training pathway. To this aim, promotion of the definition of competencies necessary to practice ICM has been one of the most important achievements fostered by ESICM through the CoBaTrICE project. Achievement of these competencies can then also be assessed through the European Diploma in Intensive Care (EDIC), an examination mapped onto the same set of competencies.

Any coherent training program should consist of a curriculum, a method of assessment and also a plan for the delivery of the program in everyday practice. Although the delivery of the program has currently many different paths from amongst the European MS, the different curriculums and assessment processes are gradually converging [6]. This is in no small part due to the CoBaTrICE group. Funded through the ESICM and the Leonardo Project of the EU, this working group has now successfully described the core competencies relating to ICM [7]. This was no minor undertaking and these competencies have now been taken on board by over seven European countries [8] and soon will also be integrated into the training pathways in the USA. In this issue of Intensive Care Medicine, the CoBaTrICE team publish their next step, which is to describe a set of quality standards that relate to the training programs [9]. The combination of the competencies together with a set of criteria that describe how a program should be run is a major statement that should enable ICM to be not just ahead of nearly every other specialty but should also enable the individual MSs to improve the quality of their own training programs. This methodology enables trainees to come to our specialty from many different parts of medicine, ultimately it is the final competencies that are important not the initial experience. Although this is a movement that has been led from the centre it will be implemented by actions at a national level. The CoBaTrICE project has now completed its first phase and has been handed over to the Clinical Training Committee of the ESICM for continued support and maintenance of the competencies dataset. This will certainly allow the harmonious development of an EDIC based around the same descriptors. This examination is becoming increasingly seen as the accreditation examination for our specialty with over ten countries now recognizing it as either the national accreditation process or as an equivalent qualification [8].

Although change at a European level is a slow and cumbersome process, the ESICM is blazing a path for the national societies and Boards to follow. Hopefully in future years ICM will have control of its own destiny and will have a harmonized set of standards across Europe so that the training and assessment processes are similar wherever they may occur. This will not only improve the quality of the training, but will also lead to improved quality of care and patient safety, whilst also enabling the free circulation of future generations of professional doctors trained in ICM between countries. Our patients and society need and expect intensive care to be leading a revolution: the one that will allow every patient to be treated according to the best standards by competent professionals in a cost-contained environment.

\section{References}

1. Moreno RP, Rhodes A (2010) The speciality of intensive care medicine: quo vadis? Int J Intensive Care 17:61

2. Vincent JL, Singer M (2010) Critical care: advances and future perspectives. Lancet 376:1354-1361
3. Moreno RP, Rhodes A (2010) Intensive care medicine: a specialty coming to LIFE. Lancet 376:1275-1276
4. Adhikari NK, Fowler RA, Bhagwanjee S, Rubenfeld GD (2010) Critical care and the global burden of critical illness in adults. Lancet 376:1339-1346 
5. Angus DC, Kelley MA, Schmitz RJ, White A, Popovich J Jr, Committee on Manpower for Pulmonary, Critical Care Societies (COMPACCS) (2000) Caring for the critically ill patient. Current and projected workforce requirements for care of the critically ill and patients with pulmonary disease: can we meet the requirements of an aging population? JAMA 284:2762-2770

6. Barrett H, Bion J (2005) An international survey of training in adult intensive care medicine. Intensive Care Med $31: 553-561$
7. CoBaTrICE Collaboration, Bion JF, Barrett H (2006) Development of core competencies for an international training programme in intensive care medicine. Intensive Care Med 32:1371-1383

8. The CoBaTrICE Collaboration (2009) The educational environment for training in intensive care medicine: structures, processes, outcomes and challenges in the European region. Intensive Care Med 35:1575-1583
9. The CoBaTrICE Collaboration (2010) International standards for programmes of training in intensive care medicine in Europe. Intensive Care Med. doi: 10.1007/s00134-010-2096-x 